\title{
ТЕОРИЯ РАЗВИТИЯ ЦИФРОВОЙ ЭКОНОМИКИ И ПРИМЕНЕНИЕ В СФЕРЕ НR ОБРАЗОВАНИЯ
}

Патутина Е.C. СамГУПС, г. Самара

В данной статье рассмотрена актуальная на сегодня проблема цифрровая экономика и ее формирование в странах: Африке, Азии, Европе, Латинской Америке, Ближнем Востоке, Северной Америке, Австралии, России. Рассмотрен актуальный вопрос внедрения и использования циирровых технологий и их влияние на эффективный метод подбора персонала. Исследуется, каким образом информационные технологические процессы оказывают большое влияние на сегодняшнюю экономику и происходящие в ней процессы. В результате проведенного исследования выделены показатели, характеризующие оценку оформленных регистрачий пользователей $в$ Интернет-ресурсах. Рассмотреньн несколько трендов в развитии инструментария для HR.

Ключевые слова: цифровая экономика, информационные технологии, Интернет-ресурсы, криптовалюты, управление персоналом, подбор персонала, оценка персонала.

Основные положения:

Автор рассмотрел взаимосвязь модели цифровой грамотности Белшоу со структурой знаний человека.

Автор использовал исследование, проведенное аналитическим агентством «We Are Social» и крупнейшей SMM-платформой «Hootsuite», использования Интернет-ресурсов позволило сформировать уровень развития экономики на примере таких мировых стран, как Африка, Азия, Европа, Латинская Америка, Ближний Восток, Северная Америка Австралия и Россия.

Введение

Современные информационные технологические процессы проявляют очень большое воздействие на экономику и общество, изменяя сложившийся экономический строй и образ жизни людей. «Цифровизация» является составной частью цифровой экономики, но, тем не менее, цифровая экономика - это название значительно более широкое. Есть всевозможные определения цифровой экономики и почти многие из них концентрируются на частных моментах, не отображая общий смысл [6]. Отдельный сегмент цифровой экономики: интернет-банкинг, электронная коммерция, крипновалюты, кибербезопасность, digital - компетенции, облачные технологии, бизнес аналитика.

Значительное количество нынешних информационных и коммуникационных технологий представляются приборами инфраструктуры 
цифровой экономики. Внедрение цифровых форм работы в экономике (выработка, распределение, обмен, использование и впоследствии переработка товарных товаров и услуг) даёт выгоду и мелким и крупным фирмам, государствам и каждому человеку. Повсеместное применение цифровых технологий идёт по всем промышленным направлениям по всей нашей планете уже практически двадцать лет.

В настоящий момент бизнес в России пришел к пониманию, что управление человеческими ресурсами - это не просто модерирование второстепенного поддерживающего бизнес-процесса. Подход, отводящий HRфункции глубоко второстепенную роль, ведет к тому, что HR-службы становятся своеобразными «королевствами в королевстве». Будучи обособленным подразделением, HR перестает ставить во главу угла интересы бизнеса в целом, живя своей самодостаточной жизнью (табл. 1) [7].

Таблица 1 - HR-тренды 2020-2030 гг.

\begin{tabular}{|c|c|c|c|}
\hline Технологии & Характеристика & Возможности & Угрозы \\
\hline $\begin{array}{l}\text { Boolean } \\
\text { search }\end{array}$ & $\begin{array}{l}\text { Запрос к поисковой системе с } \\
\text { помощью специальных } \\
\text { логических операторов, } \\
\text { помогающий обработать } \\
\text { довольно объемный поток } \\
\text { информации и получить } \\
\text { значимые результаты }\end{array}$ & $\begin{array}{lr}\text { Помогает } & \text { находить } \\
\text { лучшее из каждого } \\
\text { обращения }\end{array}$ & $\begin{array}{l}\text { Автоматизация. } \\
\text { Может выдать } \\
\text { последние } \\
\text { результаты }\end{array}$ \\
\hline $\begin{array}{l}\text { X-Ray } \\
\text { Search }\end{array}$ & $\begin{array}{l}\text { Запрос, который обеспечивает } \\
\text { полноценный разбор } \\
\text { определённого ресурса. }\end{array}$ & $\begin{array}{l}\text { Позволяет искать } \\
\text { нужную } \\
\text { информацию } \\
\text { определённых } \\
\text { сайтах, согласно } \\
\text { заданным } \\
\text { параметрам }\end{array}$ & $\begin{array}{l}\text { Так как сервис } \\
\text { бесплатный, поэтому } \\
\text { существуют } \\
\text { определённые } \\
\text { ограничения. }\end{array}$ \\
\hline $\begin{array}{l}\text { Расширения } \\
\text { Linkedin и } \\
\text { Facebook }\end{array}$ & $\begin{array}{l}\text { Социальная сеть для поиска } \\
\text { бизнес-партнеров }\end{array}$ & $\begin{array}{lr}\text { Облегчают } & \text { жизнь } \\
\text { специалисту } & \text { и } \\
\text { помогают в } & \text { поиске } \\
\text { кандидатов } & \text { на } \\
\text { свободные вакансии }\end{array}$ & $\begin{array}{l}\text { Оплата за } \\
\text { дополнительные } \\
\text { результаты }\end{array}$ \\
\hline
\end{tabular}

Источник: составлено автором

Методы

Для достижения цели и решения поставленных задач нами были использованы методы теоретического исследования, такие как: анализ и синтез, индукция и дедукция.

Обсуждение

В настоящее время человечество развивается быстрыми темпами, в том числе и технологические процессы, и информационные изобретения. В нашей стране интернет возник чуть более двадцати лет назад, но IT-сфера развивается настолько быстро и этим изменяет нашу жизнь. Люди, на сегодняшний день, не представляют свою собственную драгоценную жизнь без компьютера, 
телефонов и интернета. Эти изобретения не только помогают нам, но также экономят нашу жизнь и средства.

Многие компании применяют цифровые технологии в процессе подбора персонала - 40\% компаний используют социальные сети, а почти треть респондентов проводит видео-интервью. 15\% HR-специалистов используют в подборе чат-ботов, а 14\% - автоматизированный обзвон кандидатов. В крупных международных компаниях эти проценты выше - 58\%, 47\%, 21\% и 23\% соответственно.

В современной экономике информационные технологии играют очень большую роль. Все ресурсы компьютерной промышленности на данном этапе развития всемирного сообщества сориентированы на автоматизацию традиционных экономических процессов. Функциональное использование электронных технологий, предусмотренных информационной экономикой, ведет к распределению и потреблению социальных благ, общественного производства в более доступной форме [3].

Под ИТ процессами имеется в виду сложный комплекс методов и средств, употребляемых с целью накопления, переработки и распространения информации во всемирной глобальной сети. В дальнейшем будем рассматривать мировую статистику интернет использования (табл.2).

Таблица 2 - Мировая статистика интернет использования

\begin{tabular}{|c|c|c|c|c|c|c|}
\hline Мировые регионы & $\begin{array}{l}\text { Население } \\
\text { (оценка } \\
2019 \text { г.) }\end{array}$ & $\begin{array}{l}\text { Население } \\
\text { \% от } \\
\text { мирового }\end{array}$ & $\begin{array}{l}\text { Пользователи } \\
\text { интернета 31 } \\
\text { декабря 2018 } \\
\text { г. }\end{array}$ & $\begin{array}{l}\text { Уровень } \\
\text { проникновения } \\
\text { (\% поп.) }\end{array}$ & $\begin{array}{l}\text { Рост 2000 } \\
-2019 \text { гг. }\end{array}$ & $\begin{array}{l}\text { Пользователи } \\
\text { интернета \% }\end{array}$ \\
\hline Африка & 1287914329 & $16,9 \%$ & 453329534 & $35,2 \%$ & $9,941 \%$ & $10,9 \%$ \\
\hline Азия & 4207588157 & $55,1 \%$ & 2023630194 & $48,1 \%$ & $1,640 \%$ & $48,7 \%$ \\
\hline Европа & 827650849 & $10,8 \%$ & 704833752 & $85,2 \%$ & $570 \%$ & $17,0 \%$ \\
\hline $\begin{array}{c}\text { Латинская } \\
\text { Америка/Карибский }\end{array}$ & 652047996 & $8,5 \%$ & 437001277 & $67,0 \%$ & $2,318 \%$ & $10,5 \%$ \\
\hline бассейн & & & & & \\
\hline Ближний Восток & 254438981 & $3,3 \%$ & 164037259 & $64,5 \%$ & $4893 \%$ & $3,9 \%$ \\
\hline Океания Австралия & 31273454 & $0,6 \%$ & 28439277 & $68,9 \%$ & $273 \%$ & $0,7 \%$ \\
\hline Россия & 146510064 & $1,93 \%$ & 78564321 & $49,6 \%$ & $3467 \%$ & $2,4 \%$ \\
\hline Всего & 4634758428 & $100,0 \%$ & 4156932140 & $54,4 \%$ & $1,052 \%$ & $100,0 \%$ \\
\hline
\end{tabular}

Источник: составлено автором

По данным таблицы 2 общее количество оформленных регистраций пользователей в Интернет-ресурсах перевалило отметку в 4.6 млрд. человек, и каждый год эта цифра стремительно растёт более чем на 7\%. По данным отчёта «Global Digital» от We Are Social и Hootsuite, количество пользователей интернета в мире составляет 4, 21 млрд. чел. Максимальное воздействие на данный рост оказывают недостаточно развитые страны, где только начинается процесс информатизации.

Автор рассматривал модель цифровой грамотности Дага Белшоу, включает восемь обязательных элементов. Модель автор адаптировал со структурой знаний [3] (рис.1). 
Знания - собственность

(Владение, Распоряжение, Использование)

Циф культура - понимание культурного контекста интернет-среды

Циф конфиденциальность - способность правильно распоряжаться собственной частной информацией в сети с целью защиты частной жизни

Циф креатив - цифровая креативность способность стать частью цифр экосистемы путем создания нового контента, претворяя идеи в реальность с помощью цифровых инструментов

Циф критика- способность различать достоверную и недостоверную информацию, контент, надежные и сомнительные онлайнконтакты
Знания - функция

(Добыча, Накопление, Передача)

Циф обучение - навыки использования цифр технологий в целях саморазвития

Циф создание - умение создавать и распространять контент

Циф гражданство - способность использовать технологии, медиа безопасно, ответственно, эффективно

Циф коммуникации - умение коммуницировать в онлайн -сообществах

Рис. 1 Взаимосвязь модели цифровой грамотности со структурой знаний

Представленные на рис.1 элементы являются обязательными для экономически активных поколений, для успешного развития современного человека.

Основным отличием от традиционных технологий управления общепринятой экономики, ключевым инструментарием которой является менеджмент и рыночная модель ведения бизнеса, информационная экономика основывается на инновационном предпринимательстве, информационном инжиниринге и автоформализации экономических процессов [5].

Уже не первый год на рынке как официальные валютные системы функционируют криптовалюты. Криптовалюты - это финансовая инновация, позволяющая пропускать имеющиеся ограничения, она неизбежно оказывает большое влияние на изменчивость уровня цен и всю платежную систему. Эти цифровые денежные единицы существуют конкретно в сети и никак не связаны ни с какой-либо другой денежной единицей, ни с любой государственной валютной системой. Прогресс количества покупок, которые можно реализовать с помощью криптовалют сокращает потребность в использовании реальных денег, которые предлагают центральные банки, что и приводит к увеличению количества денег, не обсуживающих товарооборот (табл. 3) [4].

Таблица 3 - Категории товаров и услуг, оплачивающие безналично

\begin{tabular}{|c|c|}
\hline Категория & \% оплачивающих \\
\hline Связь & 85 \\
\hline Потребительские товары & 85 \\
\hline ЖКХ & 77 \\
\hline
\end{tabular}




\begin{tabular}{|c|c|}
\hline Денежные товары & 72 \\
\hline Штрафы ГИБДД, налоги & 61 \\
\hline Билеты на мероприятия & 56 \\
\hline
\end{tabular}

Источник: составлено автором

Данные табл. 3 показывают то, что все больше жителей России переходит от расчетов наличными к оплате банковскими картами; об этом, например, свидетельствует тот факт, что в 2017 году впервые количество действий по снятию с карт наличных денег не вырос, а сократился. По итогам 2017 года держатели карт на территории Российской Федерации сняли с них на $0,4 \%$ меньше средств, чем годом ранее (27, 2 трлн. руб. в денежном выражении). При всем этом 60\% платят безналично каждый день - в первую очередь за потребительские товары, связь, ЖКХ.

В России термин «цифровая экономика» получил в 2017 году официальное государственное определение, которое содержится в «Стратегии развития информационного общества в России», утвержденной Президентом РФ № 203 от 9 мая 2017 года. 28.07.2017г. Правительством Российской Федерации был принят к осуществлению проект «Цифровая экономика» как один из основных стратегических планов на период до 2025г.

Для управления данной стратегией установлены 5 базисных течений: нормативное регулирование, персонал и образование, развитие экспериментальных компетенций, информационная инфраструктура и информационная безопасность. Развитие цифровой экономики предстоит осуществить, «основываясь на накопленный научно-технический, интеллектуальный потенциал» [1].

Информационные средства подразумевают собой большую материальную значимость, и в случае, если они недостаточно защищены, несанкционированный допуск к данным ресурсам способен послужить причиной к катастрофам, а в обстоятельствах конкурентной борьбы компаний, организаций и целых стран, способен полностью изменить обстановку в пользу получившего такого рода допуск.

Заключение

Таким образом, цифровая экономика - это новый вид экономических отношений практически во всех отраслях мирового рынка, который незамедлительно развивается стремительными темпами и уже в ближайшее время, с ростом высоких технологий, может стать главным видом товарноденежных обменов на глобальном мировом уровне.

Проникновение информационных технологий в экономику приводит к ее глобализации и появлению новых экономических инструментов. По этой причине собственно незамедлительно необходимо включаться в общий информационный и технологический поток обновлений и стараться качественно их применить.

Расширение сфер деятельности специалиста по персоналу и усиление внимания к разработке «умных» систем управления активизируют необходимость в расширении компетенций HR-менеджера [4]. А это означает, 
что компетенции будущего и актуальные сегодня компетенции менеджера по управлению персоналом будут сильно отличаться. По этой причине задачей сегодняшнего HR-специалиста является задача подготовки сотрудников к трансформации «профессий» и компетенций в будущем.

\section{Список литературы}

1. Влияние цифровых технологий на развитие экономики. [Электронный pecypc] URL: http://www.vectoreconomy.ru/images/ publications/2019/. (дата обращения 29.03.2020).

2. Бердник Н.А., Быстрая Ю.С., Дейнека Л.Н., Зимовец А.В. [Текст] Экономика. 2014. - 374c.

3. Патутина Е.С. «Модель динамики экономики знаний ВУЗа» [Текст] Вестник Самарского Государственного университета путей сообщения / Самарский гос. Ун.-т. Путей сообщ. - Самара: № 1, 2013. - С. 22-27.

4. Патутина Е.С. «Исследование существующей практики сотрудничества образовательных учреждений высшего образования с основными работодателями Самарской области» [Текст] Материалы VI национальной научно - практической конференции обучающихся в магистратуре и аспирантуре «Современные проблемы финансов, экономики и менеджмента» г. Калининград, 2018. С. 35-44.

5. Цветкова Д.К. Влияние информационных технологий на экономику. [Электронный pecypc] URL: https://sibac.info/archive/meghdis/20(31) (дата обращения 29.03.2020) Влияние криптовалют на экономику. [Электронный pecypc] URL: http://popecon.ru/otrivki/629-vlijanie-kriptovalyut-na-ekonomiku.html (дата обращения 22.03.2020).

6. Информационная экономика и её структура. [Электронный ресурс] URL: https://studopedia.info/2-661.html (дата обращения 25.03.2020).

7. Информационные технологии. [Электронный ресурс] URL: https://spravochnick.ru/informacionnye_tehnologii/cifrovye_tehnologii/cifrovye_tehn ologii_v_ekonomike/ (дата обращения 29.03.2020).

8. HR-тренды. [Электронный ресурс] URL: https://hr-portal.ru/blog/hrtrendy-2020 (дата обращения 22.03.2020). 